\title{
On the enigmatic scent glands of dyspnoan harvestmen (Arachnida, Opiliones): first evidence for the production of volatile secretions
}

\author{
Günther Raspotnig • Miriam Schaider • \\ Edith Stabentheiner · Hans-Jörg Leis • \\ Ivo Karaman
}

Received: 7 January 2014/ Accepted: 11 January 2014 / Published online: 31 January 2014

(C) The Author(s) 2014. This article is published with open access at Springerlink.com

\begin{abstract}
While considerable knowledge on the chemistry of the scent gland secretions from the opilionid suborders Laniatores and Cyphophthalmi has been compiled, it is the Palpatores (Eupnoi and Dyspnoi) where chemical data are scarce. In particular, the Dyspnoi have remained nearly unstudied, mainly due to their reported general reluctance to release secretions as well as to the phenomenon of production of insoluble-and inaccessible-solid secretion. We here show that at least certain nemastomatid Dyspnoi, namely all three species of genus Carinostoma, indeed produce a volatile secretion, comprising octan-3-one, 6-methyl-5-hepten-2-one and acetophenone in species-specific combinations. In all $\mathrm{Ca}$ rinostoma spp., these volatiles are embedded in a semi-
\end{abstract}

Handling Editor: Michael Heethoff.

G. Raspotnig $(\bowtie) \cdot$ M. Schaider

Institute of Zoology, Karl-Franzens-University,

Universitätsplatz 2, $8010 \mathrm{Graz}$, Austria

e-mail: guenther.raspotnig@uni-graz.at

G. Raspotnig · H.-J. Leis

Research Unit of Osteology and Analytical Mass Spectrometry, Medical University, University Children's Hospital,

Auenbruggerplatz 30, $8036 \mathrm{Graz}$, Austria

M. Schaider

Department of Limnology and Bio-Oceanography, University of

Vienna, Althanstraße 14, 1090 Vienna, Austria

E. Stabentheiner

Institute of Plant Sciences, Karl-Franzens-University,

Schubertstraße 51, 8010 Graz, Austria

I. Karaman

Department of Biology and Ecology, Faculty of Science,

University of Novi Sad, Trg Dositeja Obradovica 2,

2100 Novi Sad, Serbia volatile, naphthoquinone matrix (mainly 1,4-naphthoquinone and 6-methyl-1,4-naphthoquinone). In detail, acetophenone and traces of naphthoquinones characterize the secretions of Carinostoma carinatum. A mixture of octan-3-one, 6-methyl-5-hepten-2-one and large amounts of naphthoquinones were found in C. elegans, and 6-methyl-5-hepten-2-one together with small amounts of naphthoquinones in the secretions of $C$. ornatum. So far, exclusively naphthoquinones had been reported from a single dyspnoan hitherto studied, Paranemastoma quadripunctatum.

Keywords Carinostoma - Nemastomatidae - Dyspnoi . Ethyl ketone $\cdot$ Methyl ketone $\cdot$ Naphthoquinones

\section{Introduction}

Prosomal scent glands (syn. defense glands, stink glands) characterize all species of harvestmen, constituting one of their most important complex synapomorphic characters (Martens 1978; Gnaspini and Hara 2007). Scent glands show major modifications across opilionid taxa and may be developed as (1) pronounced organs for chemical defense as in the Laniatores and in the Cyphophthalmi (e.g., Duffield et al. 1981; Eisner et al. 1971, 1977, 2004; Gutjahr et al. 2006; Raspotnig et al. 2005) or (2) as rather inconspicuous glands as in many Palpatores (e.g., Schaider and Raspotnig 2009; Schaider et al. 2010). From the first group, a large number of scent gland-derived products have been identified, including naphthoquinones and methyl ketones from Cyphophthalmi, alkylated benzoquinones and vinyl ketones from gonyleptoid Laniatores, phenolics from some lower grassatorean Laniatores, and small tobacco alkaloids from travunioid Insidiatores (for a summary see Raspotnig 
2012). It is, however, the Palpatores (Eupnoi and Dyspnoi) where scent glands are poorly investigated, but most heterogeneously developed, displaying transitions from the possibly plesiomorphic type of typical defense glands as still present in some Eupnoi (Holmberg 1970; Meinwald et al. 1971; Jones et al. 1976, 1977; Wiemer et al. 1978) toward more cryptic and apparently dysfunctional organs as in most Dyspnoi (see Schaider and Raspotnig 2009). First chemical data reflect this heterogeneity as well: sclerosomatid Eupnoi, at least some leiobunines, show highly volatile, acyclic ethyl ketone-rich exudates (Ekpa et al. 1985), whereas the secretions of phalangiid Eupnoi may rely on naphthoquinones (Wiemer et al. 1978). Meanwhile there is evidence for further, enormous, still undescribed chemical diversity in eupnoan subgroups (Raspotnig 2012).

On the other hand, the scent glands of dyspnoans have remained even more enigmatic: In many species, such as in all Trogulidae but also in many Ischyropsalidoidea, no secretion release can be detected at all (e.g., Pabst 1953). In trogulids, ozopores may even be hidden and covered by cuticular folds and other structures, making rapid emission of secretions impossible (Schaider and Raspotnig 2009). Paralleling these observations, a unique trend toward solidification of secretions can be observed: The secretion products of Ischyropsalis and Trogulus, for instance, were described as solids - as crystals (Juberthie et al. 1991) or as solid balls of unknown chemistry (Schaider and Raspotnig 2009). It is still unknown how such products—if at all-are eventually released to the body outside, even though a kind of sublimation, followed by "exhalation from the ozopore" has speculatively been proposed (Juberthie et al. 1991; Gnaspini and Hara 2007). In such species, the defensive role of the glands may have been lost and replaced by other functions such as territorial marking, intraspecific communication or pronounced chemical protection against microorganisms (Holmberg 1986; Juberthie et al. 1991).

However, at least certain Dyspnoi are able to release liquid secretions as well: as a first example for dyspnoan chemistry, the scent gland secretion of the nemastomatid Paranemastoma quadripunctatum was reported to contain semi-volatiles such as 1,4-naphthoquinone and 6-methyl1,4-naphthoquinone along with a series of basically nonvolatile anthraquinones (Raspotnig et al. 2010). All these compounds again form solids at room temperature and ambient pressure conditions and may be stored in their solid state in the scent gland reservoirs, but are liquefied by mixing up with enteric fluid in the course of the emission process (Schaider et al. 2011).

We here report on a further chemical class of components in dyspnoid secretions, indeed volatile compounds that characterize the scent secretions of all species of genus Carinostoma.

\section{Materials and methods}

\section{Collection of specimens}

All specimens were collected by hand or by sieving leaf litter prior to extraction of specimens in a Berlese-Tullgren apparatus. All specimens were collected alive. Carinostoma carinatum, in all 65 adult individuals of both sexes, was collected from several populations in Austria, Slovenia, Bosnia-Herzegovina, and Serbia. C. elegans (28 individuals) was from two populations in Serbia, and C. ornatum (44 individuals) from different populations in Bosnia-Herzegovina, Serbia, and Macedonia (Fig. 1; Table 1). From the location in Bosnia-Herzegovina and from one location in Serbia, the sympatric occurrence of $C$. ornatum with $C$. carinatum was recorded (Fig. 1). According to the current view on Carinostoma (e.g., Martens 1978), we thus collected all valid species of this genus. We, however, did not include representatives of "C. elegans batorligetiense" which was handled as a subspecies by Loksa (1991) but considered to be a color variation of C. elegans by others (e.g., Szalay 1952; Martens 1978). Carinostoma carinatum shows a large distributional area from the eastern Alps to the western Balkans; $C$. ornatum follows in the south, partly overlapping with south-eastern populations of $C$. carinatum, and extends toward the south-eastern Balkans. C. elegans is found from the Carpatho-Ukraine and Southern Slovakia across eastern Hungary and Romania to the northeastern parts of Serbia and to Bulgaria. Species determination of collected individuals was carried out according to Martens (1978) and Karaman (1995), mainly on the basis of the characteristic rows of bridgethorns on the dorsum of the cephalothorax (Fig. 2).

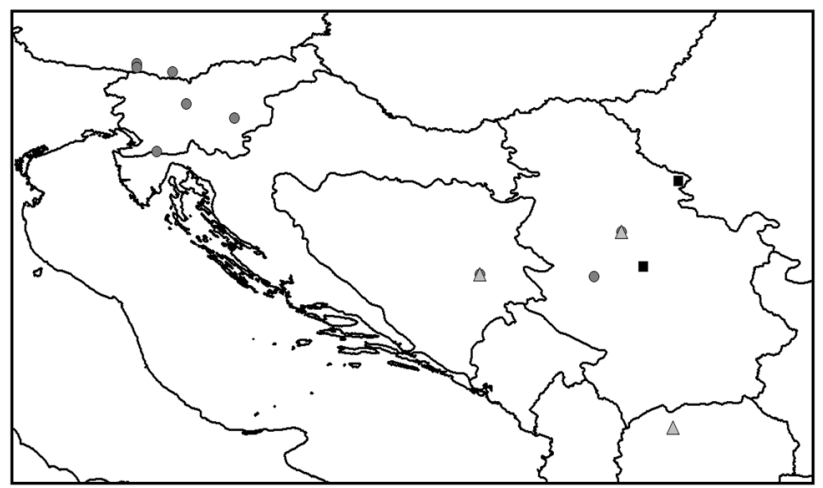

Fig. 1 Collection sites for populations of C. ornatum (gray triangles), C. elegans (black squares), and C. carinatum (gray circles). Note the sympatric occurrence of $C$. ornatum and $C$. carinatum at two collection sites (one location in Bosnia-Herzegovina, another one in Serbia). For details see Table 1 
Table 1 Collection of Carinostoma species and corresponding extracts

\begin{tabular}{|c|c|c|c|}
\hline Species & Populations, location (coordinates, altitude) & Date of collection & Extracts $^{\mathrm{a}}$ \\
\hline \multicolumn{4}{|l|}{ C. carinatum } \\
\hline \multirow[t]{4}{*}{ Austria } & $\begin{array}{l}\text { 1. Carinthia, Villach, Eichholzgraben } \\
\text { (N } 46^{\circ} 38^{\prime}, \text { E } 13^{\circ} 50^{\prime}, 590 \mathrm{~m}, \mathrm{C} . \text { Komposch leg.) }\end{array}$ & 5 April 2010 & $\begin{array}{l}\text { Pool (4 ind.), } \\
\text { pool (5ind.) }\end{array}$ \\
\hline & $\begin{array}{l}\text { 2. Carinthia, Villach, Graschelitzen } \\
\text { (N } 46^{\circ} 34^{\prime} 35^{\prime \prime} \text {, E } 13^{\circ} 49^{\prime} 57^{\prime \prime}, 600 \mathrm{~m} \text {, A. Platz leg.) }\end{array}$ & 8 October 2012 & $1 \hat{\delta}, 1$ 우 \\
\hline & $\begin{array}{l}\text { 3. Carinthia, near Ferlach, Rauth, Dixer } \\
\text { (N } 46^{\circ} 31^{\prime} 11.46^{\prime \prime}, \text { E } 14^{\circ} 19^{\prime} 56.89^{\prime \prime}, 583 \text { m, G. Raspotnig leg.) }\end{array}$ & 30 April 2010 & $\begin{array}{l}\text { Pool (4 ind.), } \\
\text { pool (4 ind.) }\end{array}$ \\
\hline & $\begin{array}{l}\text { 4. Carinthia, near Ferlach, Rauth, Moatsche } \\
\text { (N } 46^{\circ} 31^{\prime} 24.11^{\prime}, \text { E } 14^{\circ} 19^{\prime} 42.69^{\prime \prime}, 509 \mathrm{~m}, \mathrm{G} \text {. Raspotnig leg.) }\end{array}$ & 6 August 201 & 1 우 \\
\hline \multirow[t]{3}{*}{ Slovenia } & $\begin{array}{l}\text { 5. Near Ljubljana } \\
\text { (N } 46^{\circ} 6^{\prime} 19.10^{\prime \prime}, \text { E } 14^{\circ} 31^{\prime} 5.60^{\prime \prime}, 323 \mathrm{~m}, \mathrm{~S} \text {. Huber leg.) }\end{array}$ & 5 September 2012 & $6 \hat{0}, 7 ㅇ$ \\
\hline & $\begin{array}{l}\text { 6. Laknice } \\
\text { (N } 45^{\circ} 56^{\prime} 03^{\prime \prime}, \mathrm{E} 15^{\circ} 11^{\prime} 39^{\prime \prime}, 237 \mathrm{~m}, \mathrm{~T} \text {. Novak leg.) }\end{array}$ & 26 October 2013 & $4 \hat{\jmath}, 5$ 우 \\
\hline & $\begin{array}{l}\text { 7. Poljane pri Podgradu } \\
\text { (N } 45^{\circ} 29^{\prime \prime} 57^{\prime \prime}, \mathrm{E} 14^{\circ} 06^{\prime \prime} 44^{\prime \prime}, 600-700 \mathrm{~m} \text {, S. Novak \& T. Novak leg.) }\end{array}$ & 28 October 2013 & $2 \hat{\sigma}, 1$ 우 \\
\hline Bosnia-Herzegovina & $\begin{array}{l}\text { 8. Republika Srpska, Romanija Mt, Pale, Kadino selo (N } 43^{\circ} 55^{\prime} 29^{\prime \prime} \text {, E } \\
18^{\circ} 35^{\prime} 43^{\prime \prime}, 1,000 \text { m, I. Karaman leg.) }\end{array}$ & 14 August 2011 & $4 \hat{\jmath}, 1$ 우 \\
\hline \multirow[t]{2}{*}{ Serbia } & $\begin{array}{l}\text { 9. Western Serbia, Čačak, Ovčar banja } \\
\text { (N } 43^{\circ} 53^{\prime} 18.37^{\prime \prime} \text {, E } 20^{\circ} 11^{\prime} 19.31^{\prime \prime}, 370 \text { m, G. Raspotnig, P. Föttinger and } \\
\text { I. Karaman leg.) }\end{array}$ & 20 May 2009 & $1(?)$ \\
\hline & $\begin{array}{l}\text { 10. Kosmaj, near monument } \\
\left(44^{\circ} 28^{\prime} 7.28^{\prime \prime} \mathrm{N} 20^{\circ} 34^{\prime} 20.29^{\prime \prime} \mathrm{E}, 550 \mathrm{~m} \text {, I. Karaman and S. Ivković leg.) }\right.\end{array}$ & 26 October 2013 & $10 \widehat{\jmath}, 4$ 우 \\
\hline \multicolumn{4}{|c|}{ r } \\
\hline \multirow[t]{2}{*}{ Serbia } & $\begin{array}{l}\text { 11. Vršac, Vršački breg } \\
\left(45^{\circ} 7^{\prime} 14.26^{\prime \prime} \mathrm{N}, 21^{\circ} 22^{\prime} 18.42^{\prime \prime} \mathrm{E}, 190 \mathrm{~m} \text {, I. Karaman \& S. Ivković leg.) }\right.\end{array}$ & 2 November 2013 & $1 \hat{\jmath}$ \\
\hline & $\begin{array}{l}\text { 12. Kragujevac, Šumarice } \\
\left(44^{\circ} 1^{\prime} 4.72^{\prime \prime} \mathrm{N}, 20^{\circ} 52^{\prime} 45.06^{\prime \prime} \mathrm{E}, 240 \mathrm{~m} \text {, I. Karaman \& S. Ivković leg.) }\right.\end{array}$ & 5 November 2013 & $17 \widehat{\jmath}, 10$ 우 \\
\hline \multicolumn{4}{|c|}{ 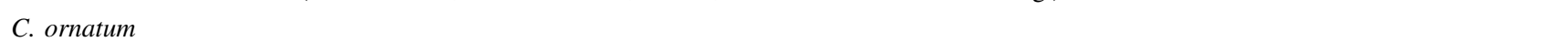 } \\
\hline Bosnia-Herzegovina & $\begin{array}{l}\text { 13. Republika Srpska, Romanija Mt, Pale, Kadino selo (N } 43^{\circ} 55^{\prime} 29^{\prime} \text {, E } \\
18^{\circ} 35^{\prime} 43^{\prime}, 1000 \text { m, I. Karaman leg.) }\end{array}$ & 14 August 2011 & $3 \hat{\jmath}, 2$ 우 \\
\hline \multirow[t]{2}{*}{ Serbia } & $\begin{array}{l}\text { 14. Kosmaj, Monastir Tresije } \\
\text { (N } 44^{\circ} 28^{\prime} 25.35^{\prime \prime} \text {, E } 20^{\circ} 34^{\prime} 6.42^{\prime \prime}, 400 \text { m, I. Karaman \& M. Horvatović } \\
\text { leg.) }\end{array}$ & 30 September 2012 & $6 \hat{0}, 3$ 우 \\
\hline & $\begin{array}{l}\text { 15. Kosmaj, near monument } \\
\text { (N } 44^{\circ} 28^{\prime} 7.28^{\prime \prime} \text { E } 20^{\circ} 34^{\prime} 20.29^{\prime \prime} 550 \text { m, I. Karaman S. Ivković leg.) }\end{array}$ & 26 October 2013 & $8 \hat{0}, 4$ 우 \\
\hline Macedonia & $\begin{array}{l}\text { 16. Skopje, Matka, near old church St. Nedela } \\
\text { (N } 41^{\circ} 56^{\prime} 56.94^{\prime \prime} \text {, E } 21^{\circ} 17^{\prime} 19.2^{\prime \prime}, 726 \text { m, M. Komnenov leg.) }\end{array}$ & 6 October 2013 & $7 \hat{\jmath}, 11$ 우 \\
\hline
\end{tabular}

${ }^{a}$ Extracts are individual extracts except for four pools, as indicated

Extraction and analysis of secretions

Scent gland secretion was obtained by whole body extraction of living individuals in $50 \mu \mathrm{l}$ of hexane or methylene chloride for $30 \mathrm{~min}$ as already described and standardized for other opilionids (e.g., Raspotnig et al. 2010). In total, 124 extracts were prepared, mostly extracts of single individuals (adults), and in some cases also pooled extracts, as summarized in Table 1. For extracts of single specimens, the gender was determined as well (Table 1). Aliquots of extracts $(1.5 \mu \mathrm{l})$ were subjected to gas chromatographicmass spectrometric analysis, using a trace gas chromatograph coupled to a DSQ I mass spectrometer (MS), both from Thermo (Vienna, Austria). The GC was equipped with a ZB-5 fused silica capillary column $(30 \mathrm{~m} \times 0.25 \mathrm{~mm}$ i.d., $0.25 \mu \mathrm{m}$ film thickness, Phenomenex, Germany). Injection

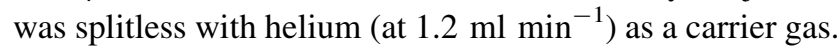
The temperature of the $\mathrm{GC}$ oven was raised from $50{ }^{\circ} \mathrm{C}$ (1 min) to $300{ }^{\circ} \mathrm{C}$ at $10{ }^{\circ} \mathrm{C} \mathrm{min}{ }^{-1}$, and then held for $5 \mathrm{~min}$ at $300{ }^{\circ} \mathrm{C}$. The ion source of the MS and the transfer line 
Fig. 2 The study objects: Dorsal view (SEM) of each male individual of $\mathbf{a}$ C. ornatum, b C. elegans, and $\mathbf{c} C$. carinatum. Note the differences in the dorsal "carinae" (rows of anvil-shaped bridge thorns: compare Karaman 1995). Arrows point to the site of ozopores
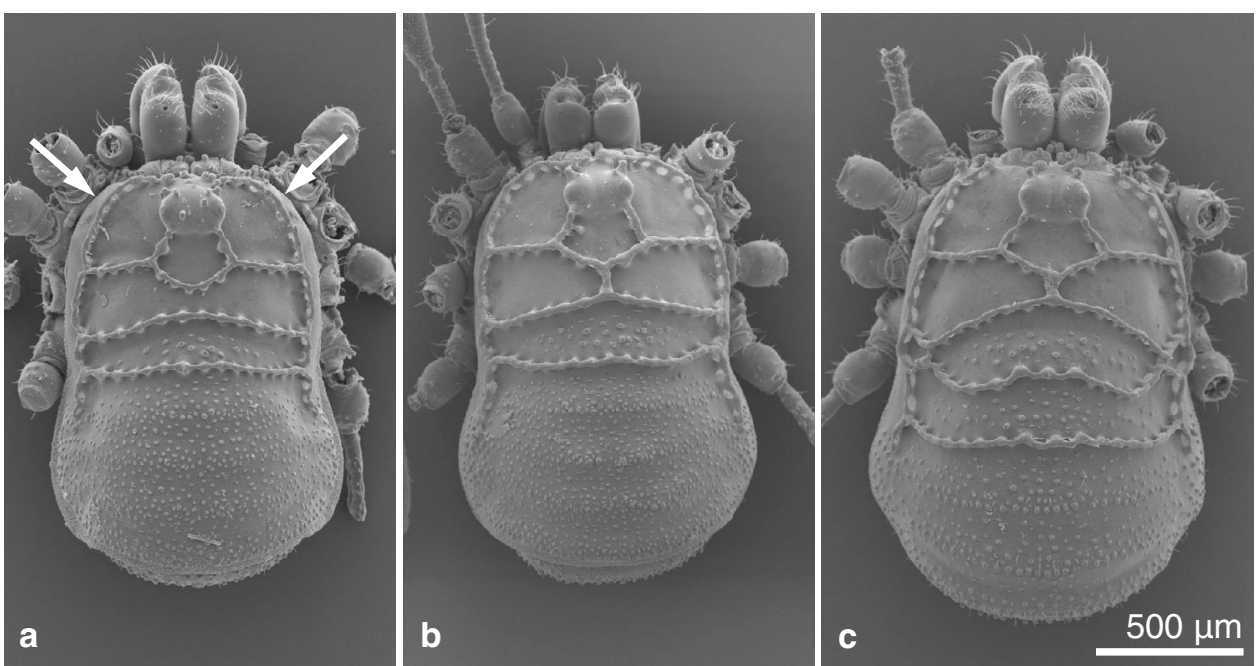

were kept at 200 and $310{ }^{\circ} \mathrm{C}$, respectively. Electron impact (EI) spectra were recorded at $70 \mathrm{eV}$. Gas chromatographic retention indices (RI) of extract components were calculated using an alkane standard mixture, following the formula $\quad \mathrm{RI}_{\mathrm{x}}=100 n_{0}+\left(100 t_{\mathrm{x}}-100 t n_{0}\right) /\left(t n_{1}-t n_{0}\right)$, with $\mathrm{x}$ : target compound; $t_{\mathrm{x}}$ : retention time of target compound; $n_{0}$ : number of carbon atoms in the alkane directly eluting before $\mathrm{x} ; t n_{0}$ : retention time of alkane directly eluting before $\mathrm{x} ; t n_{1}$ : retention time of alkane directly eluting after $\mathrm{x}$.

\section{Reference compounds and derivatization}

Authentic standards of $n$-alkanes $\left(\mathrm{C}_{7}-\mathrm{C}_{36}\right)$, acetophenone, octan-3-one, 5-methyl-heptan-3-one, 6-methyl-5-hepten-2one, 1,4-naphthoquinone and 2-methoxy-1,4-naphthoquinone for a comparison of gas chromatographic-mass spectrometric data to components found in the Carinostoma-secretion were purchased from Sigma (Vienna, Austria). 6-Methyl-1,4-naphthoquinone was prepared according to Bruce and Thomson (1952); as oxidizing reagent we used CAN (=cerium IV ammonium nitrate from Sigma, Austria). For two further compounds, namely 2-methoxy-6-methyl-1,4-naphthoquinone and 4-chloro-1,2naphthoquinone, we used known natural sources for reference, namely the secretions of $P$. quadripunctatum (Raspotnig et al. 2010) and Cyphophthalmus (formerly Siro) duricorius (Raspotnig et al. 2005). O-Methyl oximes of ketones in the Carinostoma-extracts were prepared by adding $200 \mu \mathrm{l}$ of methoxamine (MOX) reagent (=2\% methoxyamine-hydrogen chloride in pyridine, Thermo Scientific, Vienna, Austria) to $60 \mu \mathrm{l}$ of ketone-rich extracts in hexane, followed by incubation at $70^{\circ}$ for $1 \mathrm{~h}$. The products were washed twice with water, dissolved in $60 \mu \mathrm{l}$ of hexane, and an aliquot $(1.5 \mu \mathrm{l})$ was directly used for GCMS.
Scanning electron microscopy and histology

For scanning electron microscopy (SEM), specimens were fixed in Bouin, washed, dehydrated, air dried, and mounted on aluminum stubs prior to sputter coating with gold (AGAR sputtercoater, Gröpl, Tulln, Austria). Micrographs (SEM) were taken with a Philips XL30 ESEM (Philips/ FEI, Vienna, Austria) at high vacuum mode and $20 \mathrm{kV}$ accelerating voltage. For semithin cross sections $(2.5 \mu \mathrm{m})$, specimens were fixed in Bouin, washed, dehydrated, and embedded in LR-White resin (soft grade; Gröpl, Tulln, Austria). Sections were prepared on a Leica Supercut rotary microtome (Vienna, Austria) and stained with toluidine blue $\mathrm{O}$.

Evaluation of secretion profiles and multivariate statistics

Secretion profiles were evaluated by integration of peak areas of each component of the secretion and by calculation of the relative abundance of these peaks (expressed in \% peak area of whole secretion). A statistical comparison of individual secretion profiles of all three species of Carinostoma was performed in PAST (PAlaeontological STatistics, version 2.17) and was based on the method of 2D non-metric multidimensional scaling (2D-nMDS) using the Gower coefficient of dissimilarity (Gower 1967).

\section{Results}

Scent gland morphology

The paired scent glands in all species of Carinostoma are represented by small glandular sacs in the prosoma, basically comprising intima-lined secretion reservoirs (left 


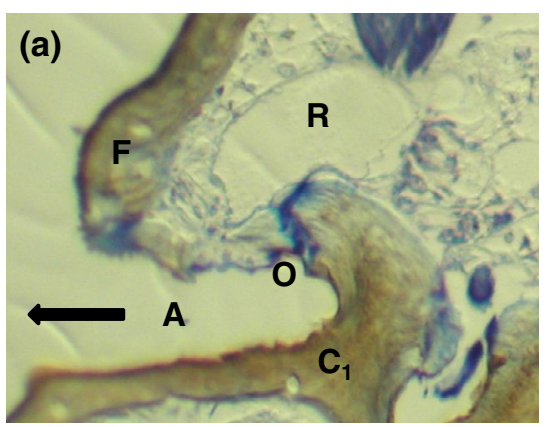

Fig. 3 Morphology of scent glands in Carinostoma. a Cross section through an individual of $C$. carinatum, at the height of coxae I, showing left scent gland reservoir $(R)$, ventrally directed ozopore $(O)$, and covering lateral fold of the cephalothorax $(F)$. Note that an

reservoir $R$ of an individual is shown in Fig. 3) opening into ozopores. Ozopores (=scent gland orifices $O$, Fig. 3; one at each side of the prosoma) are located near dorsal to coxae I (white arrows in Fig. 2). Ozopores are not visible from the outside, but hidden under a laterally protruding fold of the prosomal integument ( $F$ in Fig. 3). They are directly situated within the underside of these folds, hence being directed ventrally (Fig. 3). All products released from the scent glands must be emitted into the cavity roved over by these folds first ("atrium" $A$ in Fig. 3). The cavities (A) themselves are laterally open toward the body outside (arrow in Fig. 3).

\section{Secretions of C. ornatum}

From the 44 individual extracts of C. ornatum (24), 20ㅇ), 22 exhibited large amounts of scent gland secretions, 20 individual extracts showed only traces of scent gland secretions, and three were "empty" (i.e., not showing any peaks). The 22 secretion-containing extracts of individuals irrespective of population allocation consistently exhibited a major peak $\mathrm{A}$, followed by smaller peaks $\mathrm{D}, \mathrm{E}, \mathrm{G}$, and $\mathrm{H}$ (Fig. 4a). Mass spectral data and retention indices of compounds are summarized in Table 2.

Peak A showed the fragmentation pattern of an unsaturated terpenoid with a molecular mass of $M=126\left(\mathrm{M}^{+}\right.$at $\mathrm{m} / \mathrm{z}, 126)$. A fragment at $\mathrm{m} / \mathrm{z}$ 58(27) indicated a McLafferty rearrangement product $\left[\mathrm{C}_{3} \mathrm{H}_{6} \mathrm{O}\right]^{+}$characteristic of a methyl ketone, and the compound was suspected to be sulcatone (=6-methyl-5-hepten-2-one). A detailed comparison of the mass spectral data to the EI spectrum of 6-methyl-5-hepten-2-one from the NIST-library revealed full correspondence, and also the measured retention index matched reported values from literature (measured RI: 986; reported RI: e.g., 987 in Benzo et al. 2007). The identity of the component as 6-methyl-5-hepten-2-one was confirmed by a comparison of gas chromatographic-mass spectrometric data to an authentic sample. atrium-like cavity $(A)$ is formed at the lateral fold and the coxa I; this atrium is laterally open (arrow). b Schematic drawing of the same structure

The mass spectra of the two smaller peaks D and E indicated two naphthoquinones with molecular masses of $M=158$ and $M=172$, strongly suggesting the presence of 1,4-naphthoquinone (NQ) and 6-methyl-1,4-naphthoquinone (MNQ). The identity of the compounds as NQ and MNQ, respectively, was underlined by RIs completely matching data from literature (RIs at 1421 and 1537 in Raspotnig et al. 2012) and confirmed by comparison to the authentic compounds. Peaks $\mathrm{G}\left(\mathrm{M}^{+}\right.$at $\left.m / z, 188\right)$ and $\mathrm{H}\left(\mathrm{M}^{+}\right.$ at $m / z$ 202) were proposed to be 2-methoxy-1,4-naphthoquinone and 2-methoxy-6-methyl-1,4-naphthoquinone, respectively. Both compounds were already familiar from a previous study (Raspotnig et al. 2010). 2-Methoxy-1,4naphthoquinone was finally identified by a comparison to the authentic compound, whereas the identification of 2-methoxy-6-methyl-1,4-naphthoquinone was tentative, based on a comparison to an already known natural source, namely a naphthoquinone-rich extract of $P$. quadripunctatum (Raspotnig et al. 2010).

\section{Secretions of C. elegans}

From the 28 individual extracts of $C$. elegans $(18 \hat{\circ}, 10$ 우), 17 individuals $(12 \hat{\jmath}, 5$ 우 $)$ contained scent gland secretion, as outlined below. Secretion-loaded extracts consistently showed six peaks (Fig. 4b), five of which matched the peaks of the ornatum extracts with respect to their retention time (peaks A, D, E, G, and $\mathrm{H}$ in Fig. 4a). An additional, but generally very small peak $\mathrm{F}$ was detected, showing an unusual mass spectrum with an $\mathrm{M}+2$ ion (at $\mathrm{m} / \mathrm{z}$ 194) along with a molecular ion at $\mathrm{m} / \mathrm{z}$ 192, suggesting a chlorinated compound. The mass spectrum of the compound and its retention index fully matched data reported for 4-chloro-1,2-naphthoquinone (Raspotnig et al. 2005, 2012). For a direct gas chromatographic-mass spectrometric comparison to the authentic compound, we again used a natural source, namely a scent gland-loaded extract from Cyphophthalmus duricorius for which the compound 
Fig. 4 Typical total ion chromatograms from the three species of Carinostoma. Peak A [6-methyl-5-hepten-2-one], peak $B$ [6-methyl-5-hepten-2one + octan-3-one], peak $C$ [acetophenone], peak $D$ [1,4naphthoquinone], peak $E$ [6methyl-1,4-naphthoquinone], peak $F$ [4-chloro-1,2naphthoquinone], peak $G$ [2methoxy-1,4-naphthoquinone], peak $H$ [2-methoxy-6-methyl1,4-naphthoquinone]

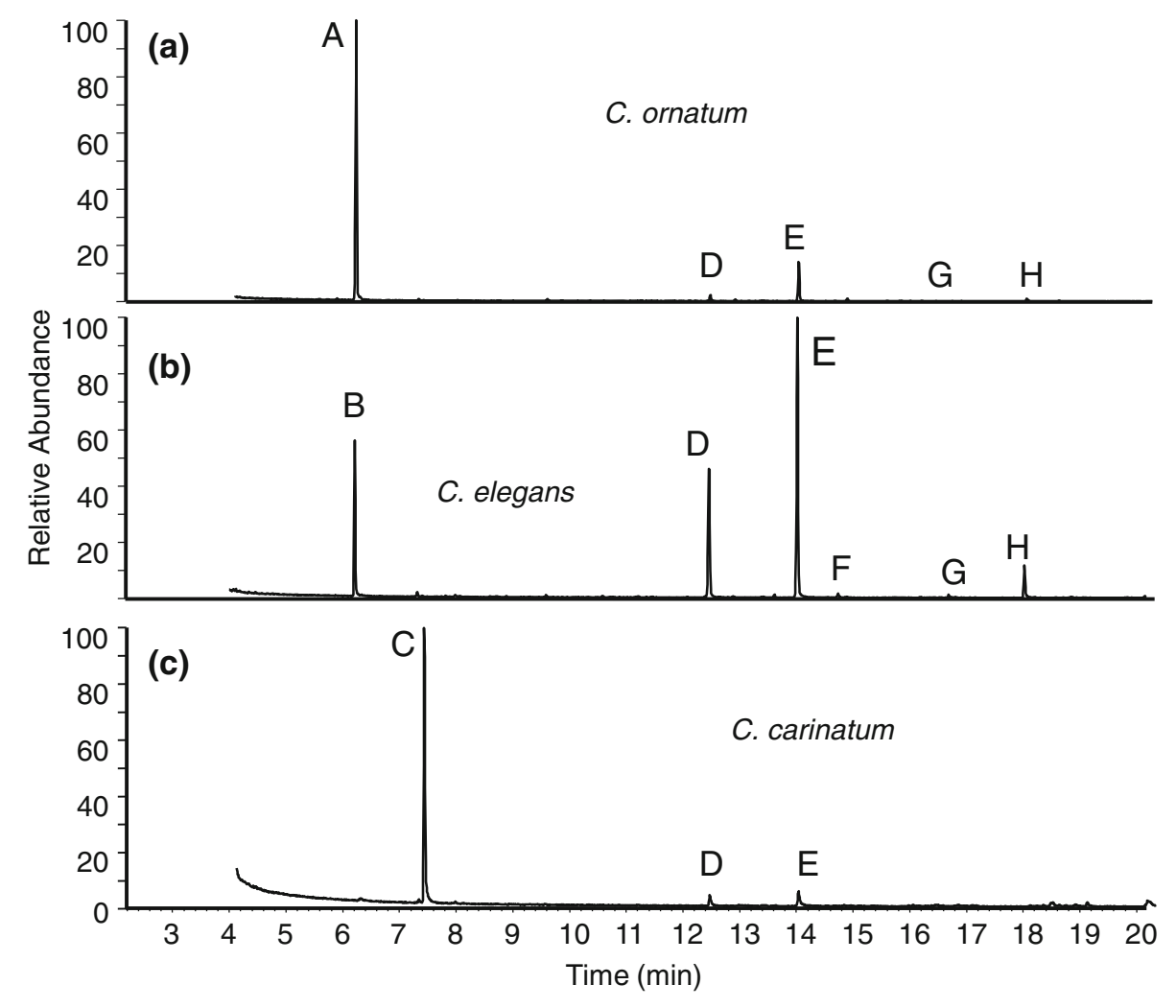

has already unambiguously been identified (Raspotnig et al. 2005).

Surprisingly, a peak eluting at exactly the same retention time as peak A of the ornatum extracts (=designated as peak $\mathrm{B}$ in the elegans extract) exhibited a mass spectrum different from already identified 6-methyl-5-hepten-2-one. This mass spectrum showed an ion of highest mass at $\mathrm{m} / \mathrm{z}$ 128 , preceded by an ion at $m / z, 126$. Since a loss of two hydrogen atoms is highly unusual and an isotopic pattern of a chlorinated compound was not given, this particular pattern indicated either (1) that the ion at $\mathrm{m} / \mathrm{z} 128$ was not the molecular ion but a fragment and that the molecular ion was not detectable under the given EI conditions, or (2) a mixed mass spectrum of two compounds eluting at the same retention time. A mass spectrum of peak $B$ by positive chemical ionization (CI+) showed ions at $\mathrm{m} / \mathrm{z} 157,155$, 129 , and 127 , interpreted as $\mathrm{M}+1$ and $\mathrm{M}+29$ adducts $\left(\mathrm{MH}^{+}\right.$ and $\mathrm{M}-\mathrm{C}_{2} \mathrm{H}_{5}{ }^{+}$). These ions indeed indicated the presence of two different compounds within peak $\mathrm{B}$, thus having molecular masses of $M=126$ and $M=128$, respectively. The compounds remained chromatographically inseparable even when changing the chromatographic conditions (lowering of injector temperature, extending the temperature program, etc., had no effect). The mixed EI mass spectrum of peak $B$, however, exhibited a striking similarity to the spectrum of already known 6-methyl-5-hepten-2-one of the ornatum extracts, showing all its fragment ions along with additional fragments at $m / z$ 57, 72, 85, 99 (base ion), and 128 (peak B, Table 2). This situation tentatively indicated that 6-methyl-5-hepten-2-one was one of the two compounds, hence representing the compound with molecular mass $M=126$, and that the additional fragments belonged to a second component. These fragments in turn appeared to be consistent with the structure of a saturated $\mathrm{C}_{8}$-ethyl ketone, as implied by the intense ion at $\mathrm{m} / \mathrm{z}, 72$ (McLafferty rearrangement) and the molecular ion at $m / z$ 128. Thus, likely candidate structures were essentially limited to octan-3-one and some of its branched isomers, with possible branching sites at $\mathrm{C} 4, \mathrm{C} 5$, and C6 only (C3 bears the keto group; branching at $\mathrm{C} 2$ is not supported by the McLafferty fragment at $\mathrm{m} / \mathrm{z}$ 72). Moreover, a methyl branching at $\mathrm{C} 4$ would lead to 4-methyl-heptan-3-one which shows a clearly different mass spectrum (intense McLafferty product at $\mathrm{m} / \mathrm{z} 86$ and not at $\mathrm{m} / \mathrm{z}$ 72) along with a much shorter retention time, as known from a paralleling study on this compound (Raspotnig, unpublished)). Thus, if branched, the branching had to occur in position C5 $(=5$ methyl-heptan-3-one) or C6 (=6-methyl-heptan-3-one). A literature survey for the RIs of the three candidate compounds revealed that only the RI of octan-3-one (reported RIs on comparable columns are about 986, e.g., RI 985 in Sari et al. 2006; RI 986 in Mohagheghzadeh et al. 2000; RI 987 in Figuérédo et al. 2006) matched the RI of 6-methyl-5hepten-2-one (measured RI for peak B: 985, Table 2). By contrast, reported RIs of the methyl-branched octanones are distinctly lower (5-methyl-heptan-3-one: RI 944 in, e.g., 
Table 2 Analytical data to extract components from C. ornatum, C. elegans, and C. carinatum

\begin{tabular}{|c|c|c|c|}
\hline $\begin{array}{l}\text { Peak } \\
\text { no. }\end{array}$ & $\mathrm{RI}^{\mathrm{b}}$ & $\begin{array}{l}\text { Mass spectrometric } \\
\text { fragmentation }(\mathrm{m} / \mathrm{z})\end{array}$ & Identified as \\
\hline A & 986 & $\begin{array}{c}126(10), 111(27), 108(78), \\
93(26), 83(16), 77(4), \\
71(26), 69(54), 68(24), \\
67(29), 58(27), 55(57), \\
53(11), 43(100), 41(54)\end{array}$ & $\begin{array}{l}\text { 6-Methyl-5-hepten-2- } \\
\text { one }\end{array}$ \\
\hline B & 985 & $\begin{array}{l}\text { 128(10), 126(10), 111(37), } \\
\text { 108(96), 99(100), 93(36), } \\
\text { 86(8), 85(17), 83(20), 77(5), } \\
\text { 73(5), 72(69), 71(79), } \\
\text { 69(43), 68(18), 67(21), } \\
\text { 58(17), 5 757), 55(34), } \\
\text { 43(89), 41(38) }\end{array}$ & $\begin{array}{l}\text { Mixture: octan-3- } \\
\text { one + 6-methyl-5- } \\
\text { hepten-2-one }\end{array}$ \\
\hline $\mathrm{C}$ & 1068 & $\begin{array}{l}\text { 120(32), 105(100), 77(98), } \\
\text { 51(25), 43(10) }\end{array}$ & Acetophenone \\
\hline D & 1421 & $\begin{array}{c}\text { 159(11), 158(100), 130(33), } \\
\text { 104(43), 102(52), 76(39), } \\
75(12), 74(12), 50(15)\end{array}$ & 1,4-Naphthoquinone \\
\hline $\mathrm{E}$ & 1547 & $\begin{array}{l}\text { 173(13), 172(100), 157(9), } \\
\text { 144(31), 118(35), 116(39), } \\
\text { 115(39), 90(20), 89(26), } \\
\text { 63(12) }\end{array}$ & $\begin{array}{l}\text { 6-Methyl-1,4- } \\
\text { naphthoquinone }\end{array}$ \\
\hline $\mathrm{F}$ & 1606 & $\begin{array}{l}\text { 194(48), 192(100), 166(5), } \\
\text { 164(19), 157(50), 138(3), } \\
\text { 136(10), 129(60), 104(19), } \\
\text { 101(33), 77(5), 76(22), } \\
\text { 75(17), 74(11), 50(9) }\end{array}$ & $\begin{array}{l}\text { 4-Chloro-1,2- } \\
\text { naphthoquinone }\end{array}$ \\
\hline G & 1782 & $\begin{array}{l}\text { 189(10), 188(100), 173(46), } \\
\text { 160(40), 159(38), 158(55), } \\
\text { 131(10), 130(18), 104(11), } \\
\text { 102(52), 101(13), 89(69), } \\
\text { 76(20) }\end{array}$ & $\begin{array}{l}\text { 2-Methoxy-1,4- } \\
\text { naphthoquinone }\end{array}$ \\
\hline $\mathrm{H}$ & 1912 & $\begin{array}{l}203(11), 202(100), 187(48), \\
\text { 174(34), 173(54), 172(25), } \\
\text { 145(18), 144(25), 131(20), } \\
\text { 116(88), 115(61), 103(90), } \\
\text { 89(48), 86(13), 77(46), } \\
\text { 69(25), 63(36), 57(38), } \\
51(12)\end{array}$ & $\begin{array}{l}\text { 2-Methoxy-6-methyl- } \\
\text { 1,4-naphthoquinone }\end{array}$ \\
\hline
\end{tabular}

${ }^{\mathrm{b}}$ Retention index on a ZB-5 column

Morteza-Semnani et al. 2006; 6-methyl-heptan-3-one: RI 941 in, e.g., Usai et al. 2003). Eventually, an authentic sample of octan-3-one led to a peak at the same retention time as 6-methyl-5-hepten-2-one under our given chromatographic conditions (measured RI for authentic octan-3one: 985). Furthermore, a 1:1 mixture of the two synthetic components (=6-methyl-5-hepten-2-one + octan-3-one $)$ resulted in one single, sharp peak with RI 985, exhibiting a mixed mass spectrum fully consistent with the spectrum of peak B from the C. elegans extracts (Fig. 5) and thus confirming the identity of octan-3-one as the second compound within peak B. To eventually separate the two compounds in the $C$. elegans extracts and determine their ratio, we prepared their $O$-methyl oximes: derivatization of synthetic octan-3-one with MOX resulted in the generation of two isomeric $O$-methyl oximes (in 1:1 ratio) at RIs 1060 and 1068, respectively, whereas the MOX derivatives of 6-methyl-5-hepten-2-one (arising in 1:2 ratio) were separable at RIs 1071 and 1090 (Table 3; Fig. 6). MOX derivatization of the C. elegans extracts revealed exactly the same derivatives, matching in both retention times and mass spectra (Fig. 6). As shown in the synthetic samples, the derivatization to $O$-methyl oximes was quantitative, and the ratio of the derivatives well corresponded to the originally present ratio of the two components. Alternatively, the ratio of the two original components could also be calculated directly from their mixed mass spectrum by a comparison of fragment ions at $\mathrm{m} / \mathrm{z}, 111$ (base ion in the spectrum of 6-methyl-5-hepten-2-one under the given conditions) and $\mathrm{m} / \mathrm{z} 99$ (base ion in the spectrum of octan-3-one). For instance, in spectra where these ions showed the same intensity, the ratio of the two components was 1:1. Different ratios of ions $\mathrm{m} / \mathrm{z} 111: \mathrm{m} / \mathrm{z}, 99$ directly reflected the quantitative composition of peak B in the C. elegans extracts, as subsequently verified by a quantification of the MOX derivatives for all 17 secretion-loaded $C$. elegans extracts. As a result, 6-methyl-5-hepten-2-one was always found to be the major component in the two-compound mixture, on average constituting $2 / 3$ (calculated $67.0 \pm 10.0 \%$ ) of peak B (max. $80 \%$, min. $50 \%)$.

\section{Secretions of C. carinatum}

From the 65 individuals of $C$. carinatum, 48 individual extracts and 4 pooled extracts were prepared. All pooled extracts and 14 individual extracts contained scent gland secretion, as outlined below. These extracts basically exhibited three peaks (C, D, and E, Fig. 4c), with the latter two peaks representing the already known naphthoquinones, NQ and MNQ, respectively. Both quinones generally occurred in very small amounts (combined amounts were on average about $11 \%$ of the secretion, see Table 4) and in most individuals even in traces only. In several samples, e.g., in all extracts from the (five) individuals from the population in Bosnia (see Table 1), no trace of them was detected. Peak C, however, was consistently present as the major component of the secretion (Table 4). Its mass spectrum indicated a low molecular weight $\left(\mathbf{M}^{+}\right.$at $m / z$ 120) aromatic (phenyl cation at $m / z$ 77) and completely matched the EI spectrum of acetophenone. The measured retention index was RI 1068, being basically consistent with the RI for acetophenone from literature as well (e.g., RI 1068 in Costa et al. 2009). We finally compared the compound to synthetic acetophenone, showing full correspondence in both retention time and mass spectrum. 
Fig. 5 EI-Mass spectra of synthetic a 6-methyl-5-hepten2-one, b octan-3-one, and c mixed mass spectrum of both (ratio 1:1). Compare to the mass spectrum of peak $B$ in Table 2
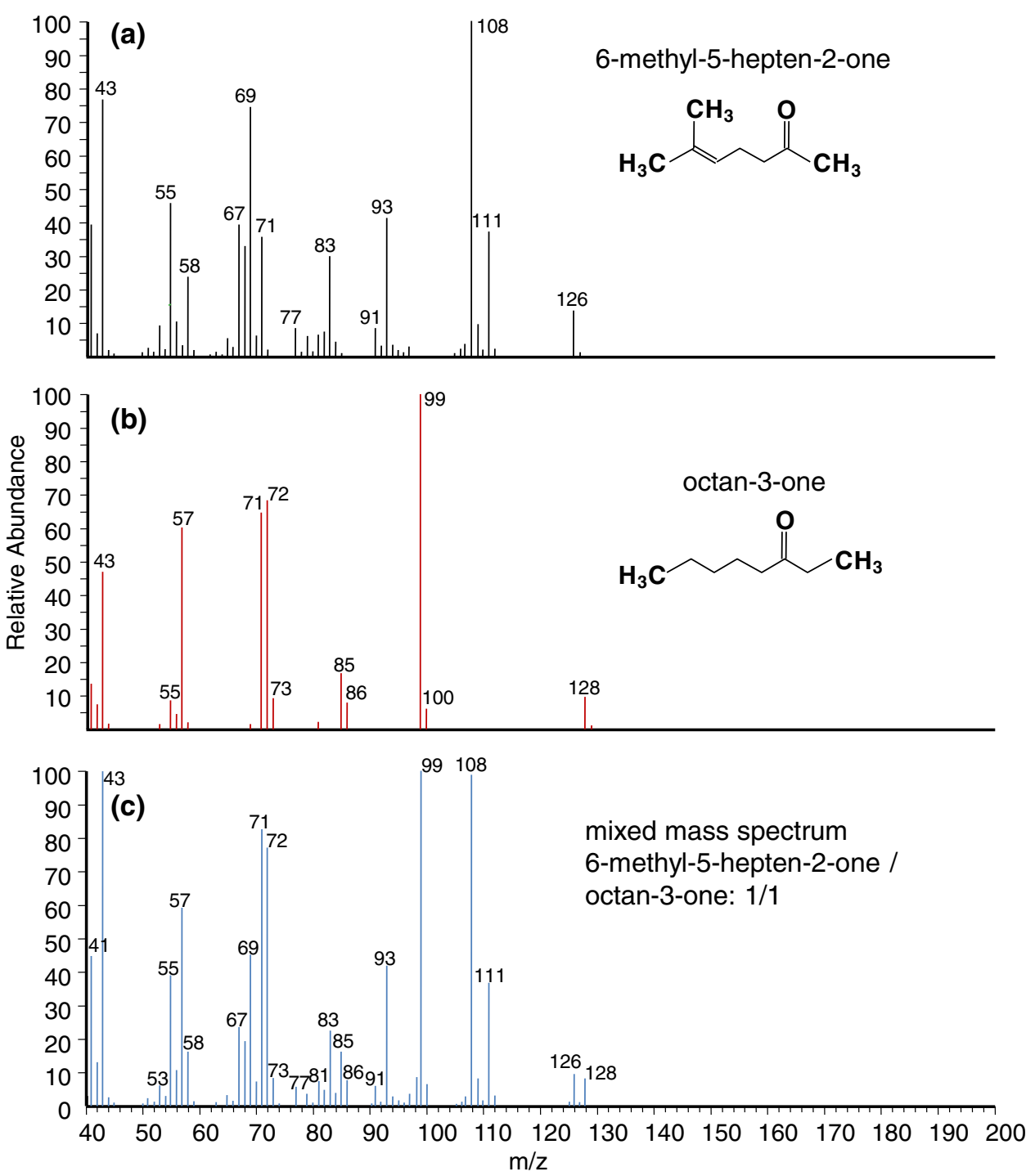

Species specificity, sex specificity, interpopulation differences and effect of sympatry

The chemical homogeneity or heterogeneity of the secretions of the three Carinostoma species was evaluated by calculating individual secretion profiles based on the relative abundance of single secretion components in the chromatograms. Average profiles for each species are given in Table 4. All profiles (=53 individual extracts; pooled extracts were excluded) were subject to a multivariate statistical comparison by 2D-nMDS, resulting in three distinct chemical clusters corresponding to the three species (Fig. 7). Intraspecifically, (1) no discrimination between the profiles of individuals from different populations was noticed (overlap in nMDS, not shown), and (2) no sexually dimorphic secretions occurred (overlap in nMDS, not shown), all of which underlined the stability of secretion profiles as species-specific characters. In two of our collections (at one locality in Bosnia-Herzegovina and one in Serbia, see Table 1) we noted the sympatric occurrence of $C$. ornatum with $C$. carinatum. Extracts of individuals from these populations either showed 6-methyl-5-hepten-2-one (in C. ornatum) or acetophenone (in C. carinatum), exactly as described for these species in general. Extracts of $C$. ornatum from sympatric populations seemed to exhibit a slightly lower amount of naphthoquinones (measured as total of NQ and MNQ in the secretion,) than $C$. ornatum-individuals from allopatric populations (sympatric populations-total average content of NQ + MNQ: $10.51 \pm 10.86 \%$ of secretion, $n=8$; allopatric populations-total average content of NQ + MNQ: $19.38 \pm 22.01 \%, n=13$; normal distribution of values not given). A difference between the medians was statistically not significant, as revealed by a two-tailed (Wilcoxon) Mann-Whitney $U$ test $(U=44$, exact $p=0.5787$ ). A sympatric occurrence of $C$. elegans and $C$. ornatum was not given in any collection. 
Absolute amounts of secretions

To evaluate how much secretion can be produced and stored, the absolute amounts of MHO in two selected individuals of $C$. ornatum from the Macedonian population

Table 3 Separation of octan-3-one and 6-methyl-5-hepten-2-one by $O$-methyl oximation

\begin{tabular}{|c|c|c|c|}
\hline Peak & compound & $\mathrm{RI}^{\mathrm{a}}$ & $\begin{array}{l}\text { Mass spectrometric } \\
\text { fragmentation }(\mathrm{m} / \mathrm{z})\end{array}$ \\
\hline & $\begin{array}{l}\text { 6-Methyl-5-hepten-2- } \\
\text { one (synthetic) }\end{array}$ & 986 & $\begin{array}{c}\text { 126(13), 111(39), 108(100), } \\
\text { 93(42), 83(24), 77(6), } \\
\text { 71(27), 69(56), 68(23), } \\
\text { 67(27), 58(18), 55(38), } \\
\text { 53(7), 43(56), 41(32) }\end{array}$ \\
\hline $\mathrm{A}_{1}$ & $\begin{array}{l}\text { 6-methyl-5-hepten-2- } \\
\text { one } O \text {-methyl oxime } \\
\text { isomer } 1\end{array}$ & 1071 & $\begin{array}{l}\text { 155(0.2), 108(3), 97(8), 87(2), } \\
82(100), 79(6), 69(33), \\
67(32), 55(6), 42(7), 41(17)\end{array}$ \\
\hline $\mathrm{A}_{2}$ & $\begin{array}{l}\text { 6-methyl-5-hepten-2- } \\
\text { one } O \text {-methyl oxime } \\
\text { isomer } 2\end{array}$ & 1090 & $\begin{array}{l}\text { 155(9), 140(9), 124(16), } \\
\text { 112(8), 109(21), 108(17), } \\
\text { 107(16), 96(7), 94(9), } \\
87(65), 83(72), 82(100), \\
\text { 69(91), 67(30), 55(32), } \\
42(48), 41(55)\end{array}$ \\
\hline & $\begin{array}{l}\text { Octan-3-one } \\
\quad \text { (synthetic) }\end{array}$ & 985 & $\begin{array}{l}\text { 128(9), 99(100), 86(8), 85(18), } \\
\text { 73(12), 72(78), 71(79), } \\
\text { 57(61), 55(9), 43(44) }\end{array}$ \\
\hline $\mathrm{B}_{1}$ & $\begin{array}{l}\text { Octan-3-one } O \text {-methyl } \\
\text { oxime isomer } 1\end{array}$ & 1060 & $\begin{array}{l}157(11), 128(27), 114(25), \\
110(6), 101(100), 86(6), \\
82(7), 81(6), 71(16), 70(19), \\
69(11), 56(20), 42(24)\end{array}$ \\
\hline $\mathrm{B}_{2}$ & $\begin{array}{l}\text { Octan-3-one } O \text {-methyl } \\
\text { oxime isomer } 2\end{array}$ & 1068 & $\begin{array}{l}\text { 157(9), 128(26), 114(23), } \\
\text { 110(7), 101(100), 86(5), } \\
\text { 82(6), 81(6), 71(16), 70(19), } \\
\text { 69(9), 56(22), 42(24) }\end{array}$ \\
\hline
\end{tabular}

${ }^{\text {a }}$ Retention index on a ZB-5 column were exemplarily quantified, using a calibration curve for authentic MHO. Extracts of the selected specimens (both +) had already revealed the largest amounts of secretion of all individuals analyzed (on the basis of peak areas), thus possibly giving an impression of the (near) maximal amount of secretion per individual. We calculated $1.9 \mu \mathrm{g}$ and $3.0 \mu \mathrm{g}$ of MHO per individual, respectively. Based on the secretion profiles given above, these amounts would account for about $85 \%$ of the whole secretion (Table 4), thus roughly implying secretion amounts per individual in the lower $\mu \mathrm{g}$ range.

\section{Discussion}

A novel dyspnoid scent gland "ecotype"

Following a study on P. quadripunctatum (Raspotnig et al. 2010), this is the second investigation into the scent gland chemistry of dyspnoan harvestmen, providing first evidence for the production and emission of volatile components-i.e., "scent" in the literal sense. So far, dyspnoans have frequently been regarded as emitting no secretions at all, though scent glands are well developed across all dyspnoan taxa. The reported reluctance or even inability to release secretions may thus refer to certain dyspnoan subgroups only (e.g., Pabst 1953; Shear 2010; see below). In consideration of the results for Carinostoma and on the basis of currently available information from literature, at least three ecological types of dyspnoan scent glands can now be distinguished (compare Schaider et al. 2010). (1) A glandular type that relies on the production of solid secretion. This type (="solid glandular type") is taxonomically not well defined and includes taxa such as
Fig. 6 Separation and identification of 6-methyl-5hepten-2-one/octan-3-one by $O$-methyloximation. a MOX treatment of synthetic 6-methyl5-hepten-2-one leads to two isomeric $O$-methyloximes $\left(A_{l}\right.$, $A_{2}$ ) in a ratio of $1: 2$. b MOX of synthetic octan-3-one leads to two isomeric $O$-methyloximes $\left(B_{1}, B_{2}\right)$ in a ratio of $1: 1$. c MOX of a $C$. elegans extract showing the $O$-methyloxime isomers of both compounds $\left(A_{1}, A_{2}, B_{1}\right.$, $B_{2}$ ). Mass spectral data to all $O$-methyloximes are summarized in Table 3

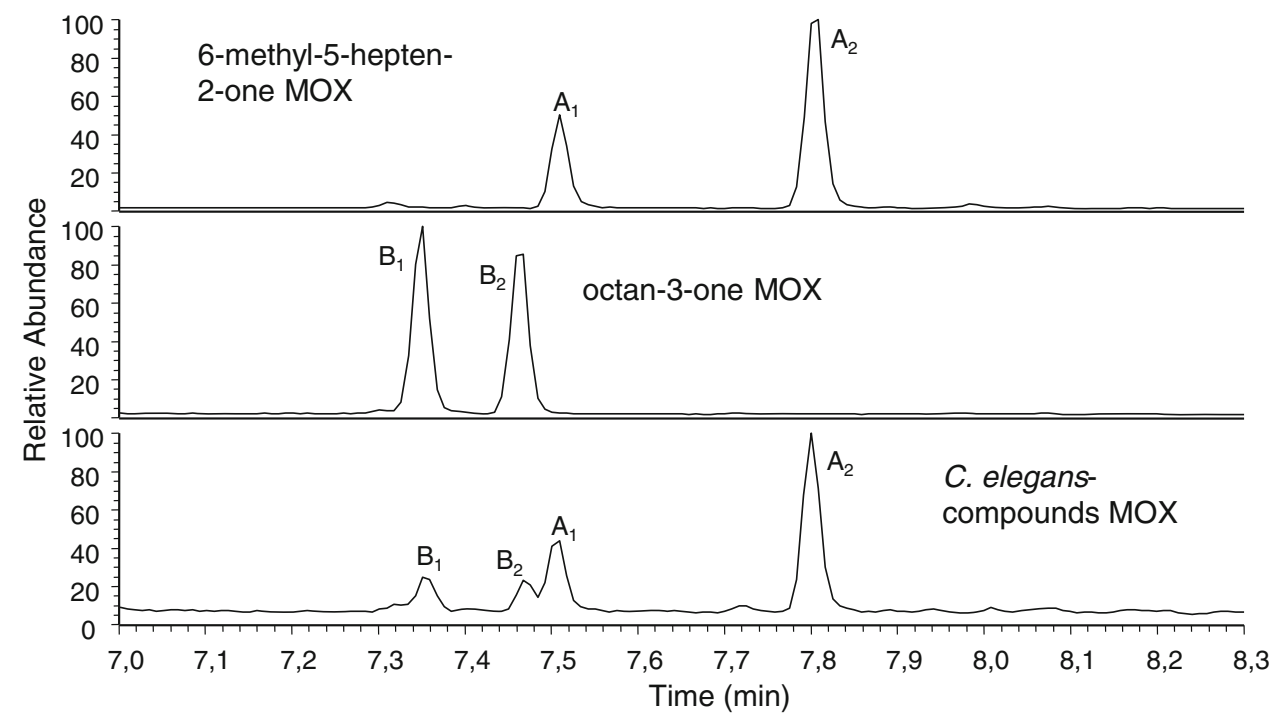


Table 4 Scent gland secretion profiles of C. carinatum, C. ornatum, and C. elegans

\begin{tabular}{|c|c|c|c|}
\hline Compounds & C. carinatum $^{\mathrm{a}}$ & C. ornatum ${ }^{\mathrm{a}}$ & C. elegans ${ }^{\mathrm{a}}$ \\
\hline Octan-3-one & - & - & $6.6 \pm 2.5$ \\
\hline 6-Methyl-5-hepten-2-one & - & $84.0 \pm 19.8$ & $14.9 \pm 7.0$ \\
\hline Acetophenone & $88.8 \pm 11.4$ & - & - \\
\hline 1,4-Naphthoquinone & $5.2 \pm 5.9$ & $6.6 \pm 9.6$ & $24.9 \pm 6.2$ \\
\hline $\begin{array}{l}\text { 6-Methyl-1,4- } \\
\text { naphthoquinone }\end{array}$ & $5.9 \pm 7.3$ & $8.6 \pm 9.9$ & $47.1 \pm 4.4$ \\
\hline $\begin{array}{l}\text { 4-Chloro-1,2- } \\
\text { naphthoquinone }\end{array}$ & - & Trace & $1.1 \pm 0.7$ \\
\hline $\begin{array}{l}\text { 2-Methoxy-1,4- } \\
\text { naphthoquinone }\end{array}$ & - & $0.2 \pm 0.4$ & $0.3 \pm 0.3$ \\
\hline $\begin{array}{l}\text { 2-Methoxy-6-methyl-1,4- } \\
\text { naphthoquinone }\end{array}$ & $0.1 \pm 0.4$ & $0.6 \pm 1.0$ & $5.1 \pm 1.8$ \\
\hline
\end{tabular}

$\bar{a}$ Evaluation of profiles was based on extracts containing amounts of secretions large enough for quantification (=calculation of peak areas), in detail on 14 individual extracts of $C$. carinatum, 22 extracts of $C$. ornatum, and 17 extracts of C. elegans. Profiles are given in $\%$ peak area of whole secretion

Trogulidae, Dicranolasmatidae, partly Nemastomatidae (Ortholasmatinae), and also certain Ischyropsalidoidea such as Ischyropsalis and some Ceratolasmatinae (Pabst 1953; Juberthie et al. 1991; Shear 2010; Schaider et al. 2010; Raspotnig, unpublished observations). Secretion of this type is not extractable or, at least, could so far not be extracted by different organic solvents (e.g., Schaider and Raspotnig 2009; Shear 2010). In all these taxa, emission of secretion cannot be recognized, and the natural mode of secretion release, if there is any, is unknown or highly speculative as outlined in "Introduction". (2) A second glandular ecotype ("semi-volatile glandular type") is characterized by the production of solid or viscous secretion that is liquefied in the course of the emission process and then may be applied in liquid form. This type of secretion includes semi-volatiles such as naphthoquinones and solids such as anthraquinones, which so far represented the only chemically known secretion components from the Dyspnoi. This type of secretion is characteristic for certain Nemastomatidae such as for genera Paranemastoma (Raspotnig et al. 2010), Histricostoma, and Mediostoma (Raspotnig, unpublished), and possibly others. (3) The volatiles produced by Carinostoma spp. characterize a third ecological type of scent glands among the Dyspnoi. We cannot assess the taxonomic distribution of this "volatile glandular type" for the time being, but preliminary investigations indicate that a number of nemastomatines, including all species of Nemastoma fall into this category (Raspotnig, unpublished). This third glandular type may be characterized as containing different volatiles in a semivolatile naphthoquinone matrix. The absolute amounts of

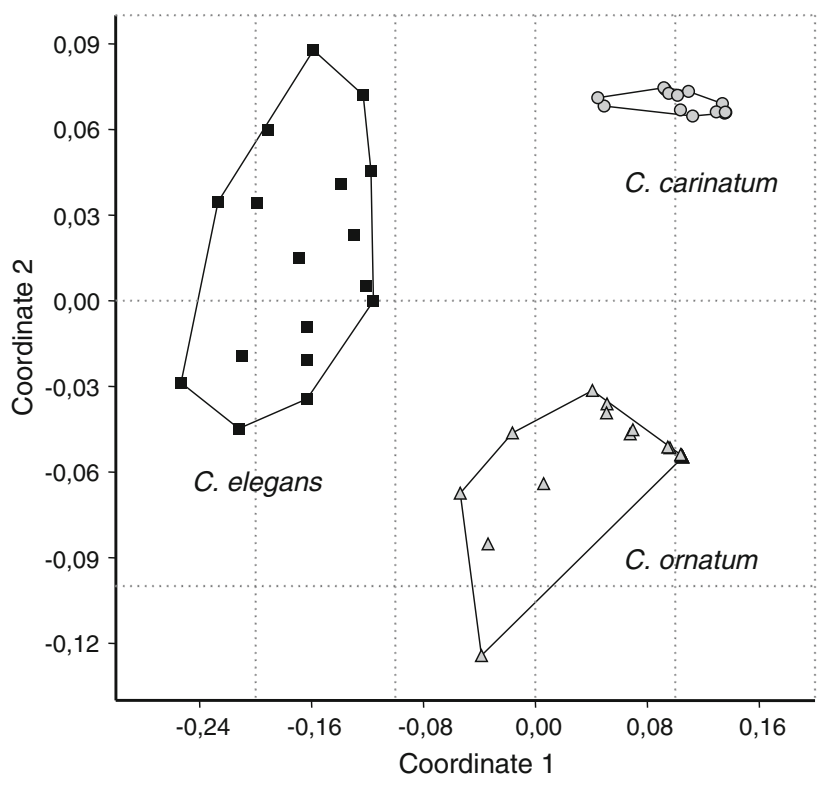

Fig. 7 Statistical discrimination of secretion profiles from individuals of different species of Carinostoma by multidimensional scaling (2DnMDS) of Gower dissimilarity. Three homogenous, clearly distinguishable chemical clusters are indicated well corresponding to the three different species

volatiles produced, as e.g., found for $C$. ornatum, are comparable to those from other Opiliones: Species of the laniatorean Holoscotolemon for instance (body length 3-4 mm) produce about $15 \mu \mathrm{g}$ of secretion/individual (Raspotnig et al. 2011). This is about five to ten times more than the detected maximum amount in $C$. ornatum individuals (body length about $1.5 \mathrm{~mm}$; body volume less than $1 / 10$ of that in Holoscotolemon). Interestingly, and though not exactly quantified, $C$. carinatum appeared to produce the least amounts of secretion of all Carinostoma species: this was tentatively indicated by generally low peak areas or only trace amounts of acetophenone (compared to MHO peaks of $C$. ornatum) and underlined by the rather small size of scent glands as found in histological sections (Fig. 3).

Volatile ketones from Dyspnoi: phylogenetic implications

Scent glands and their secretions have been the focus of opilionid chemosystematics for many years (Roach et al. 1980; Duffield et al. 1981; Hara et al. 2005; Caetano and Machado 2013), indeed representing a promising model system to study the evolution of secretion chemistry in exocrine glands in general (e.g., Raspotnig 2012). It certainly is an ambitious goal to logically and comprehensively explain the taxonomic distribution of chemical characters across the secretions of all extant opilionid taxa, 
but first approaches (mainly on Laniatores) are already available (e.g., Hara et al. 2005; Caetano and Machado 2013). For cyphophthalmid/palpatorean taxa, however, an enormous bulk of work still has to be processed to generate a comprehensive chemical database that allows a reliable reconstruction of the evolutionary history of secretion compounds. Dyspnoans, in particular, had virtually been excluded from the recently revived field of scent glandbased opilionid chemosystematics (e.g., Raspotnig 2012): the predominating dyspnoan trend toward increasing solidification of secretion (finally resulting in the "solid glandular type") clearly impeded any chemosystematic approach, simply by a general inaccessibility of secretions (e.g., Shear 2010) or, at least, by methodological difficulties regarding their extraction (Raspotnig et al. 2010). Moreover, this trend toward solidification must be considered a highly derivative dyspnoan condition and is thus probably less valuable for reconstructing major trends of scent gland chemistry among the higher groups of Opiliones. From previous scent gland research, a few chemical classes of scent gland products have turned out to be well suited for a continuous and comprehensive reconstruction of opilionid chemistry: Such chemosystematically useful classes of compounds are certainly the laniatorean phenols and benzoquinones (Caetano and Machado 2013; Rocha et al. 2013a) as well as the cyphophthalmid/palpatorean naphthoquinones (see below). Another widespread and chemosystematically important class may be represented by scent gland-derived ketones (e.g., Ekpa et al. 1985; Raspotnig 2012). Indeed, all three Carinostoma-volatiles (6-methyl-5-hepten-2-one, octan-3-one, acetophenone) are ketones, and a comparably ketone-rich chemistry is meanwhile also indicated for Nemastoma and related genera (Raspotnig, unpublished). Thus, there is at least first evidence for further ketones among the Dyspnoi, possibly even representing the characteristic core chemistry of dyspnoan secretions of the volatile glandular type in general. To class the Carinostoma ketones (or the putative "volatile glandular-type" ketones) into the current chemosystematic picture of Opiliones, at least two major possible scenarios have to be considered: In a first scenario, the compounds may have evolved anew and represent products of a possibly independent biosynthetic route of the "volatile glandular type" in dyspnoan harvestmen. This scenario is simple and may be supported by the involvement of compounds such as 6-methyl-5-hepten-2-one-an exocrine compound relatively widespread in the secretions of other arthropods, e.g., in dolichoderine ants and certain coleopterans (Cavill et al. 1956; Schildknecht et al. 1976). Comparably, also octan-3-one has been reported from the secretions of various insects, in particular from the mandibular glands of myrmicine ants (e.g., Crewe et al 1969). In terms of a postulated "semiochemical parsimony" (sensu Blum 1996), such compounds have evolved several times independently in different taxonomic groups, obviously due to a common physico-chemical suitability as allomones.

Within a certain taxon, however, such compounds may show chemosystematic relevance, opening up the view onto a second scenario: scent gland-derived ketones seem to systematically "pervade" the secretions of Opiliones and are characteristic for all Cyphophthalmi so far investigated (methyl ketones), sclerosomatid Eupnoi (ethyl ketones), and a distinct group of gonyleptid Laniatores (vinyl ketones). These compounds have been detected in the Dyspnoi (methyl- and ethyl ketones) as well. While the laniatorean vinyl ketones clearly have an independent evolutionary origin, representing a synapomorphy of some gonyleptid subfamilies (Rocha et al. 2011, 2013b; Caetano and Machado 2013; Wouters et al. 2013), the idea of a common ancestry of the ketones from scent gland secretions of Cyphophthalmi/Palpatores is intriguing and has already been proposed (Raspotnig 2012). The results for Carinostoma (or as expected for the volatile glandular-type secretions in general) may support this view, though we are aware that the available data on cyphophthalmid/palpatorean chemistry base is still poor and biased (particularly for palpatorean secretions), currently not allowing too farreaching conclusions. Though 6-methyl-5-hepten-2-one and octan-3-one are new compounds for the secretions of opilionids, they can - at least chemically — be assigned to methyl and ethyl ketones, as found in cyphopthalmids and sclerosomatids, respectively (Ekpa et al. 1985; Raspotnig et al. 2005, 2012; Jones et al. 2009). The third compound, acetophenone, also shows a ketone structure and even belongs to the pool of already reported cyphophthalmid secretion compounds (Raspotnig et al. 2005). Unfortunately, and contrasting with first insights into ketone biosynthesis in gonyleptids (Rocha et al. 2013b), nothing is known about the biosynthetic routes to ketone components in the Cyphophthalmi/Palpatores. A common route to these compounds in cyphophthalmids, Eupnoi and Dyspnoi, however, might indeed support an assumed common ketone ancestry. In this case, the Carinostoma volatiles represented a first chemosystematic link to the ketones of Cyphophthalmi and Sclerosomatidae and a first step toward a much more elaborated view on the chemosystematic overall picture of Opiliones.

\section{Evidence for common naphthoquinones}

By contrast, the presence of naphthoquinones associated with the Carinostoma secretion was not too surprising: naphthoquinones are common in opilionid scent glands (except laniatorean glands) and may indeed represent a part of the phylogenetically old exocrine equipment of the 
Opiliones (Raspotnig 2012). In particular, 1,4-NQ and 6-MNQ have meanwhile been reported from cyphophthalmids of three different families hitherto analyzed (Raspotnig et al. 2005, 2012) and at least exemplarily from phalangiid Eupnoi (Wiemer et al. 1978) as well as from nemastomatid Dyspnoi (Raspotnig et al. 2010). The finding of 1,4-NQ and 6-MNQ in Carinostoma further underlines the status of these compounds as ancestral characters of cyphophthalmid/palpatorean scent gland secretions. The finding of 4-chloro-1,2naphthoquinone in the secretions of $C$. elegans and (in traces) in C. ornatum, however, was unexpected since chloronaphthoquinones have been considered a synapomorphy of cyphophthalmids and have not been detected in any other opilionid or in any other arthropod yet (e.g., Raspotnig et al. 2012). Nothing is known on their actual distribution among dyspnoans, but the occurrence of these exceptional compounds in Carinostoma implies a common ancestry with Cyphophthalmi as well.

Functionally, the involvement of naphthoquinones in an effective operation of the Carinostoma secretion is still not clear. Their origin in the scent glands of Carinostoma is virtually certain: In $P$. quadripunctatum, a large nemastomatid close to Carinostoma (Schönhofer et al. 2013) these naphthoquinones are major components of the secretions, and scent gland reservoirs even appear reddish by naphthoquinones after excision. We assume an analogous situation to be true for species of Carinostoma. The process of secretion emission, however, may clearly differ between these two genera: When Paranemastoma applies its secretion in the course of natural operation, naphthoquinones (and anthraquinones) are liquefied by enteric fluid via a rather intricate mechanism, probably involving the conduction of enteric fluid into scent gland reservoirs and the subsequent discharge of a quinone-loaded mixture (Schaider et al. 2011). In Carinostoma, however, a particular liquefaction process of the naphthoquinones by mixing up with enteric fluid has never been observed and may not be necessary either. It is very likely that the naphthoquinones are already dissolved in the volatile ketone fraction in the reservoirs and that an already accomplished mixture is ejected.

Acknowledgments This work was supported by a grant from the Austrian Science Fund (FWF), project number P21819-B16 and by the Ministry of Education and Science of the Republic of Serbia, grant no. III43007. We thank Christian Komposch (Öko-Team, Graz, Austria), Alexander Platz (Graz, Austria), Siegfried Huber (Mühlhofen, Germany), Ljuba Slana Novak (Slovenj Gradec, Slovenia), and Tone Novak (Maribor, Slovenia) for providing many specimens of $C$. carinatum from South Carinthia and Slovenia, respectively. We are indebted to Marjan Komnenov (Skopje, Macedonia) for collecting individuals from a Macedonian population of C. ornatum. Furthermore, we want to express our sincere thanks to Michael Heethoff (Darmstadt, Germany) and Axel Schönhofer (Mainz, Germany) for their helpful comments on the manuscript.
Open Access This article is distributed under the terms of the Creative Commons Attribution License which permits any use, distribution, and reproduction in any medium, provided the original author(s) and the source are credited.

\section{References}

Benzo M, Gilardoni G, Gandini C, Caccialanza G, Finzi PV, Vidar G, Abdo S, Layedra P (2007) Determination of the threshold concentration of main odorants in essential oils using gas chromatography-olfactometry incremental dilution technique. J Chromatogr A 1150:131-135

Blum MS (1996) Semiochemical parsimony in the Arthropoda. Annu Rev Entomol 41:353-374

Bruce DB, Thomson RH (1952) Aromatic keto-enols. Part II. Some new 2:3-dihydro-1:4-naphthoquinones and -anthraquinones. J Chem Soc 1952:2759-2766

Caetano D, Machado G (2013) The ecological tale of Gonyleptidae (Arachnida, Opiliones) evolution: phylogeny of a neotropical lineage of armoured harvestmen using ecological, behavioural and chemical characters. Cladistics 29:589-609

Cavill GWK, Ford DL, Locksley HD (1956) The chemistry of ants. I. Terpenoid constituents of some Australian Iridomyrmex species. Aust J Chem 9:288-293

Costa R, De Fina MR, Valentino MR, Rustaiyan A, Dugo P, Dugo G, Mondello L (2009) An investigation on the volatile composition of some Artemisia species from Iran. Flavour Fragr J 24:75-82

Crewe RM, Brand JM, Fletcher DJC (1969) Identification of an alarm pheromone in the ant Crematogaster peringueyi. Ann Entomol Soc Am 62:1212

Duffield RM, Olubajo O, Wheeler JW, Shear WA (1981) Alkylphenols in the defensive secretion of the nearctic opilionid, Stygnomma spinifera. J Chem Ecol 7:445-452

Eisner T, Kluge AF, Carrel JE, Meinwald J (1971) Defense of phalangid: liquid repellent administered by leg dabbing. Science 173:650-652

Eisner T, Jones TH, Hicks K, Silberglied RE, Meinwald J (1977) Quinones and phenols in the defensive secretions of neotropical opilionids. J Chem Ecol 3:321-329

Eisner T, Rossini C, Eisner M (2004) Chemical defense of an opilionid (Acanthopachylus aculeatus). J Exp Biol 207: 1313-1321

Ekpa O, Wheeler JW, Cokendolpher JC, Duffield RM (1985) Ketones and alcohols in the defensive secretion of Leiobunum townsendi Weed and a review of the known exocrine secretions of Palpatores (Arachnida: Opiliones). Comp Biochem Physiol 81B:555-557

Figuérédo G, Cabassu P, Chalchat J-C, Pasquier B (2006) Studies of Mediterranean oregano populations. VIII. Chemical composition of essential oils of oreganos of various origins. Flavour Fragr $\mathbf{J}$ 21:134-139

Gnaspini P, Hara MR (2007) Defense mechanisms. In: Pinto-daRocha R, Machado G, Giribet G (eds) Harvestmen-The Biology of Opiliones. Harvard University Press, Cambridge, pp 374-399

Gower JC (1967) A comparison of some methods for cluster analysis. Biometrics 23:623-637

Gutjahr M, Schuster R, Alberti G (2006) Ultrastructure of dermal and defence glands in Cyphophthalmus duricorius Joseph, 1868 (Opiliones: Sironidae). Acta Zool Bulg 20:41-48

Hara MR, Cavalheiro AJ, Gnaspini P, Santos DYAC (2005) A comparative analysis of the chemical nature of defensive 
secretions of Gonyleptidae (Arachnida: Opiliones: Laniatores). Biochem Syst Ecol 33:1210-1225

Holmberg RG (1970) The odiferous glands of some Palpatores Phalangida (Opiliones) (Arachnida). M.Sc.Thesis, Saskatoon, University of Saskatchewan (Canada), $134 \mathrm{pp}$

Holmberg RG (1986) The scent glands of Opiliones: a review of their function, pp 131-133. In: Eberhard WG, Lubin YD, Robinson BC (eds) Proceedings of the 9th international congress of arachnology (Panama 1983), Smithsonian Institution Press, Washington

Jones TH, Conner WE, Kluge AF, Eisner T, Meinwald J (1976) Defensive substances of opilionids. Experientia 32:1234-1235

Jones TH, Meinwald J, Hicks K, Eisner T (1977) Characterization and synthesis of volatile compounds from the defensive secretions of some "daddy longlegs" (Arachnida: Opiliones: Leiobunum spp.). Proc Natl Acad Sci USA 74:419-422

Jones HJ, Shear WA, Giribet G (2009) The chemical defences of a stylocellid (Arachnida, Opiliones, Stylocellidae) from Sulawesi with comparisons to other Cyphophthalmi. J Arachnol 37: $147-150$

Juberthie C, Lopez A, Juberthie-Jupeau L (1991) Les glandes odorantes des Ischyropsalidae souterrains (Opilions): ultrastructure and role. Mem Biospeol 18:39-46

Karaman IM (1995) Fauna opilionida (Arachnida, Opiliones) durmitorskog podrucja. Master thesis. Prirodno-matematicki fakultet Univerzitet u Novom Sadu

Loksa I (1991) The harvestmen (Opiliones) fauna of the Bátorliget Nature Reserves (NE Hungary). In: Mahunka S (ed) The Bátorliget Nature Reserves-after forty years, 1990. Hungarian Natural History Museum, Budapest, pp 685-689

Martens J (1978) Spinnentiere, Arachnida. Weberknechte, Opiliones. Die Tierwelt Deutschlands, vol 64. Teil, Gustav Fischer Verlag, Jena, $449 \mathrm{pp}$

Meinwald J, Kluge AF, Carrel JE, Eisner T (1971) Acyclic ketones in the defensive secretion of a "daddy longlegs" (Leiobunum vittatum). Proc Natl Acad Sci USA 68:1467-1468

Mohagheghzadeh A, Shams-Ardakani M, Ghannadi A (2000) Volatile constituents of callus and flower-bearing tops of Zataria multiflora Boiss. (Lamiaceae). Flavour Fragr J 15:373-376

Morteza-Semnani K, Akbarzadeh M, Changizi S (2006) Essential oils composition of Stachys byzantina, S. inflata, S. lavandulifolia and S. laxa from Iran. Flavour Fragr J 21:300-303

Pabst W (1953) Zur Biologie der mitteleuropäischen Trogulidae. Zool $\mathrm{Jb}$ Abt Syst 82:2-46

Raspotnig G (2012) Scent gland chemistry and chemosystematics in harvestmen. Biol Serbica 34:5-18

Raspotnig G, Fauler G, Leis M, Leis HJ (2005) Chemical profiles of scent gland secretions in the cyphophthalmid opilionid harvestmen, Siro duricorius and S. exilis. J Chem Ecol 31:1353-1368

Raspotnig G, Leutgeb V, Schaider M, Komposch C (2010) Naphthoquinones and anthraquinones from scent glands of a dyspnoid harvestman, Paranemastoma quadripunctatum. J Chem Ecol 36: $158-162$

Raspotnig G, Schaider M, Föttinger P, Komposch C, Karaman I (2011) Nitrogen-containing compounds in the scent gland secretions of European cladonychiid harvestmen (Opiliones, Laniatores, Travunioidea). J Chem Ecol 37:912-921

Raspotnig G, Schwab J, Karaman I (2012) High conservatism in the composition of scent gland secretions in the Cyphophthalmi: evidence from Pettalidae (Arachnida, Opiliones). J Chem Ecol 38:437-440

Roach B, Eisner T, Meinwald J (1980) Defensive substances in opilionids. J Chem Ecol 6:511-516

Rocha DFO, Hamilton K, Gonçalves CCS, Machado G, Marsaioli AJ (2011) 6-Alkyl-3,4-dihydro-2H-pyrans: chemical secretion compounds in neotropical harvestmen. J Nat Prod 74:658-663

Rocha DFO, Wouters FC, Zampieri DS, Brocksom TJ, Machado G, Marsaioli AJ (2013a) Harvestmen phenols and benzoquinones: characterisation and biosynthetic pathway. Molecules 18: 11429-11451

Rocha DFO, Wouters FC, Machado G, Marsaioli AJ (2013b) First biosynthetic pathway of 1-hepten-3-one in Iporangia pustulosa (Opiliones). Sci Rep 3:3156

Sari M, Biondi DM, Kaabeche M, Mandalari G, D'Arrigo M, Bisignano G, Saija A, Daquino C, Ruberto G (2006) Chemical composition, antimicrobial and antioxidant activities of the essential oil of several populations of Algerian Origanum glandulosum Desf. Flavour Fragr J 21:890-898

Schaider M, Raspotnig G (2009) Unusual organization of scent glands in Trogulus tricarinatus (Opiliones, Trogulidae): evidence for a non-defensive role. J Arachnol 37:78-83

Schaider M, Komposch C, Stabentheiner E, Raspotnig G (2010) Preliminary studies on the morphology of scent glands of soildwelling harvestmen (Arachnida, Opiliones). Acta Soc Zool Bohemicae 74:97-101

Schaider M, Komposch C, Stabentheiner E, Raspotnig G (2011) Functional anatomy of scent glands in Paranemastoma quadripunctatum (Opiliones, Dyspnoi, Nemastomatidae). J Morph 272:1182-1191

Schildknecht H, Berger D, Krauss D, Connert J, Gehlhaus J, Essensbreis H (1976) Defense chemistry of Stenus comma (Coleoptera: Staphylinidae). J Chem Ecol 2:1-11

Schönhofer AL, McCormack M, Tsurusaki N, Martens J, Hedin M (2013) Molecular phylogeny of the harvestmen genus Sabacon (Arachnida: Opiliones: Dyspnoi) reveals multiple Eocene-Oligocene intercontinental dispersal events in the Holarctic. Mol Phyl Evol 66:303-315

Shear WA (2010) New species and records of ortholasmatine harvestmen from México, Honduras, and the western United States (Opiliones, Nemastomatidae, Ortholasmatinae). ZooKeys 52:9-45

Szalay L (1952) Opiliones aus der Umgebung von Bátorliget und dem Mecsek-Gebirge in Ungarn. Acta biol Acad Sci Hungar 2: 307-310

Usai M, Atzei A, Pintore G, Casanova I (2003) Composition and variability of the essential oil of Sardinian Thymus herba-barona Loisel. Flavour Fragr J 18:21-25

Wiemer DF, Hicks K, Meinwald J, Eisner T (1978) Naphthoquinones in the defensive secretion of an opilionid. Experientia 34: 969-970

Wouters FC, Rocha DFO, Conçalves CCS, Machado G, Marsaioli AJ (2013) Additional vinyl ketones and their pyranyl ketones in gonyleptid harvestmen (Arachnida: Opiliones) suggest these metabolites are widespread in his family. J Nat Prod 76:1559-1564 